\title{
Novel Distributed Optimal Control of Battery Energy Storage System in an Islanded Microgrid with Fast Frequency Recovery
}

\author{
Xiao Qi ${ }^{1, *(1)}$, Yan Bai ${ }^{1}$, Huanhuan Luo ${ }^{2}$, Yiqing Zhang ${ }^{3}$, Guiping Zhou ${ }^{2}$ and Zhonghua Wei ${ }^{2}$ \\ 1 School of Control and Computer Engineering, North China Electric Power University, Beijing 102206, China; \\ by@ncepu.edu.cn \\ 2 State Grid Liaoning Electric Power Supply Co., Ltd., Shenyang 110004, China; rawn@163.com (H.L.); \\ 18900911559@163.com (G.Z.); wzh_fw@ln.sgcc.com.cn (Z.W.) \\ 3 Synergy Innovation Center for Energy Economics of Shandong, Shandong Institute of Business and \\ Technology, Yantai 264005, China; zyq_751105@163.com \\ * Correspondence: qixiao@ncepu.edu.cn; Tel.: +86-010-6177-2102
}

Received: 18 July 2018; Accepted: 27 July 2018; Published: 27 July 2018

\begin{abstract}
Highly intermittent renewable energy sources pose new challenges to microgrid operation and control. Thus, many distributed control strategies have been proposed to solve this problem. However, for most previous studies, the system frequency fluctuation can be further controlled on the basis of the optimal control strategy. This paper proposes a novel distributed optimal control strategy of a battery energy storage system in an islanded microgrid to provide desired optimal control performance and fast frequency recovery. The proposed control strategy is implemented through a multi-agent system based on consensus algorithm, which only requires information collected through a local communication network. Furthermore, the measurement of supply-demand mismatch is replaced by the control signal obtained from a supplementary controller with the improved linear active disturbance rejection control algorithm. The stability of microgrid frequency can be greatly enhanced through this improvement. Finally, the validity of proposed method is demonstrated by various case studies which are given in this paper.
\end{abstract}

Keywords: distributed optimal control; islanded microgrid; battery energy storage system; linear active disturbance rejection control; frequency recovery

\section{Introduction}

The microgrid, as is defined by the Consortium for Electric Reliability Technology Solutions (CERTS), is the integration of interconnected load and distributed energy resources and acts as a single controllable entity with respect to the traditional power grid [1,2]. However, due to the high intermittence of renewable energy sources (RESs), new challenges have been posed to the operation and control of microgrid.

In order to overcome this problem, battery energy storage systems (BESSs) [3] are installed in microgrids due to their fast dynamic responses and accurate performances in absorbing excessive power and compensating for insufficient power. In [4], a BESS was used to provide fast active power compensation and improve performances of load frequency control. In [5], a novel state-of-charge-based control strategy is proposed to smooth the output fluctuation of a hybrid system. Finally, in [6], a cooperation control strategy for wind power and battery storage is proposed to provide frequency regulation. The supply-demand balance can be well guaranteed through an appropriately designed control strategy of BESSs. Additionally, the rotating inertia of a microgrid is significantly reduced due to the widely use of power electronic converters, which will result in greater 
frequency oscillation if there exists supply-demand mismatch [7,8]. Hence, in order to stabilize system frequency during the optimal control process, it's significantly important to employ more effectively control strategies.

Generally, there are three main control strategies, including centralized control strategy $[9,10]$, decentralized control strategy (DCS) [11,12], and distributed control strategy. The centralized control strategy, which is implemented through a central controller, requires global information of a microgrid. That is to say, a complex communication network and a powerful central controller are essential. Additionally, microgrid will be broken down by the single-point fault of the central controller. In contrast, components based on fully decentralized control strategy are only controlled by the local information and do not need to communicate with each other, which enhances system robustness. However, because of the deficiency of broader available information, it is not effective to use all available resources of microgrid for optimization [13]. Conversely, DCS only needs the information obtained from the local communication network.

Recently, there are various DCSs for microgrid operation and control. In [14], an incremental cost consensus algorithm is proposed to illustrate the use of distributed control in a microgrid, and the algorithm was extended by considering the generator capacity. Then, in [15], based on the incremental cost consensus algorithm, an improved distributed control strategy is proposed through changing the updating rules to minimize total power loss. Similarly, in [16], another improved distributed control strategy based on the consensus algorithm is proposed for microgrid optimal control. Moreover, the distributed cooperative control strategy proposed in [17] also effectively maintains total power balance and minimizes total power loss. Then, inspired by the dynamic average consensus estimation method, an optimal control strategy is proposed in [18] to minimize the generation cost of components in a distributed manner. With further investigation of the distributed algorithm, authors in $[17,18]$ propose a novel distributed strategy in [13] to coordinate multiple BESSs under wind uncertainties. The fully distributed power dispatch method proposed in [19] achieves rapid frequency recovery and minimizes generation cost for a microgrid, in which a subgradient-based consensus algorithm is used to recover frequency and an average consensus algorithm is used to eliminate frequency disturbance caused by measurement error. However, although the aforementioned literatures can realize distributed optimal control of microgrid, the fluctuation of frequency can be further controlled during the optimal control process.

Microgrids based on the previous optimal methods still have small supply-demand deviation after the optimization process. It can be neglect in traditional power systems. However, the frequency of a microgrid changes more rapidly and sharply with the existence of supply-demand mismatch. Additionally, considering the stochastic characteristic of wind turbine generators and other renewable energy sources, it's necessary to propose a more available control strategy which can provide faster frequency recovery during optimization process. Therefore, this paper proposes a novel distributed optimal control strategy to realize the minimization of BESS cost, and to simultaneously provide fast frequency recovery. The multi-agent system (MAS) framework [20] and the consensus-based optimization algorithm are employed in this paper. Furthermore, the measurement of supply-demand mismatch is replaced by the control signal calculated by a supplementary controller based on the improved linear active disturbance rejection control (ILADRC) algorithm [21] to realize fast frequency recovery. Compared with methods in $[14,16]$ and other literatures, the frequency stability of a microgrid can be better guaranteed based on the proposed method.

This paper is arranged following: Section 2 introduces consensus algorithm and ILADRC theory. Section 3 formulates the problem. The proposed control strategy and its implementation are described in Section 4. Simulation results and analysis are shown in Section 5. Finally, conclusions are drawn in Section 6. 


\section{Preliminary}

\subsection{Consensus Algorithm}

The theory of a consensus algorithm is described in this section. $\mathcal{G}=(\mathcal{N}, \mathcal{E})$ expresses a network. $\mathcal{N}=1,2, \cdots, n$ denotes nodes set, $\mathcal{E}$ denotes edges set. Edge $(i, j) \in \mathcal{E}$ denotes the connected nodes. The initial value of node $i$ is $x_{i}(0) \in R$. And the initial values of entire network can be expressed as $x(0)=\left(x_{1}(0), x_{2}(0), \cdots, x_{n}(0)\right)^{T}$. The purpose of Multi-Agent System is to obtain the value of $\frac{1}{n} \sum_{i=1}^{n}\left(x_{i}(0)\right)$ which can be calculated through the consensus algorithm. The iterations are as

$$
x_{i}(t+\tau)=w_{i i} x_{i}(t)+\sum_{j \in \mathcal{N}_{i}} w_{i j} x_{j}(t)
$$

where $t=0,1,2, \cdots, w_{i j}$ denotes the calculation weight of $x_{j}$ at node $i$.

Then, Equation (1) is described as

$$
x(t+\tau)=W x(t)
$$

where

$$
W=\left(\begin{array}{cccc}
w_{11} & w_{12} & \cdots & w_{1 n} \\
w_{21} & w_{22} & \cdots & w_{2 n} \\
\vdots & \vdots & \ddots & \vdots \\
w_{n 1} & w_{n 2} & \cdots & w_{n n}
\end{array}\right)
$$

The converging speed of Multi-Agent System depends on $W$. Thus, this paper adopts an improved metropolis algorithm [22] and $w_{i j}$ can be described as

$$
w_{i j}= \begin{cases}\frac{2}{n_{i}+n_{j}+1}, & j \in \mathcal{N}_{i} \\ 1-\sum_{j \in \mathcal{N}_{i}} \frac{2}{n_{i}+n_{j}+1}, & i=j \\ 0, & \text { otherwise }\end{cases}
$$

where $\mathcal{N}_{i}$ denotes the neighbor agents of agent $i, n_{i}$ denotes the amount of agents which are connected with agent $i$, and $n_{j}$ denotes the amount of agents which are connected with agent $j$.

\subsection{Improved Linear Active Disturbance Rejection Control}

In a system, the output is usually denoted by $y$, the control signal is denoted by $u$, the external disturbance is denoted by $d$. Then, the system can be expressed following

$$
\ddot{y}=b u+f(\dot{y}, y, u, d)
$$

where $f$ denotes the sum of external and internal disturbance.

The system can be described in Equation (5). Then, in order to estimate $y, \dot{y}$, and $f$, a linear extended state observer (LESO) is designed following Equation (6).

$$
\left\{\begin{aligned}
\dot{x}_{1} & =x_{2} \\
\dot{x}_{2} & =x_{3}+b_{0} u \\
\dot{x}_{3} & =\dot{f} \\
y & =x_{1}
\end{aligned}\right.
$$

where $b_{0}$ denotes the estimation value of $b$. 


$$
\left\{\begin{array}{l}
\dot{z}_{1}=z_{2}+\beta_{1}\left(y-z_{1}\right) \\
\dot{z}_{2}=z_{3}+\beta_{2}\left(y-z_{1}\right)+b_{0} u \\
\dot{z}_{3}=\beta_{3}\left(y-z_{1}\right)
\end{array}\right.
$$

where

$$
\left[\beta_{1}, \beta_{2}, \beta_{3}\right]=\left[3 \omega_{0}, 3 \omega_{0}^{2}, \omega_{o}^{3}\right]
$$

With the estimation of disturbance, system control signal can be expressed as Equation (7). This also transforms system into an integral cascade following Equation (8).

$$
\begin{gathered}
u=\frac{u_{0}-z_{3}}{b_{0}} \\
\ddot{y}=f+u_{0}-z_{3} \approx u_{0}
\end{gathered}
$$

Finally, the control law of ILADRC is following [21]

$$
u_{0}=k_{p}(r-y)-k_{d} \dot{y}
$$

\section{Problem Formulation}

A framework of an islanded microgrid is presented in Figure 1, which consists of multiple BESSs, two wind power generators, and three load demands. In a system's stable state, the active power balance of an islanded microgrid can be represented as:

$$
\sum_{i \in N_{B}} P_{B E S S_{i}}+\sum_{i \in N_{R}} P_{R E S_{i}}=\sum_{i \in N_{L}} P_{L_{i}}
$$

where $P_{B E S S_{i}}, P_{R E S_{i}}$, and $P_{L_{i}}$ are the output power of $i$ th BESS, RES, and load demand, respectively. Furthermore, $N_{B}, N_{R}$, and $N_{L}$ are the index sets of BESSs, RESs, and load demands, respectively.

Although the wind power generator can make contributions to the frequency regulation through the inertia control strategy, the output power cannot be accurately controlled due to its intermittent nature. Additionally, the wind power generator is almost undispatchable. In contrast, because of the fast dynamic responses and accurate performances, the BESSs can be dispatched to eliminate the supply-demand mismatch caused by the intermittence of RESs and unpredicted fluctuation of load demand.

The cost function for BESSs is often modeled as:

$$
\begin{aligned}
& C\left(P_{\left.B_{E S S_{i}}\right)}\right)=\frac{1}{2} a_{i}\left(P_{\text {BESS }_{i}}\right)^{2}+b_{i} P_{\text {BESS }_{i}} \\
& \text { s.t. } \quad P_{B E S S_{i}}^{\min } \leq P_{\text {BESS }_{i}} \leq P_{B E S S_{i}}^{\max }
\end{aligned}
$$

where $C$ is the cost, and nonnegative $a_{i}$ and $b_{i}$ are the cost coefficients. $P_{B E S S_{i}}^{\min }$ and $P_{B E S S_{i}}^{\max }$ are the lower and upper bounds of ith BESS power output, respectively.

Then, the optimal control problem of BESSs can be described as follows:

$$
\begin{array}{ll}
\text { Min } & \sum_{i \in N_{B}} C\left(P_{B E S S_{i}}\right) \\
\text { s.t. } & \sum_{i \in N_{B}} P_{B E S S_{i}}+\sum_{i \in N_{R}} P_{R E S_{i}}=\sum_{i \in N_{L}} P_{L_{i}} \\
& P_{B E S S_{i}}^{\min } \leq P_{B E S S_{i}} \leq P_{B E S S_{i}}^{\max }
\end{array}
$$




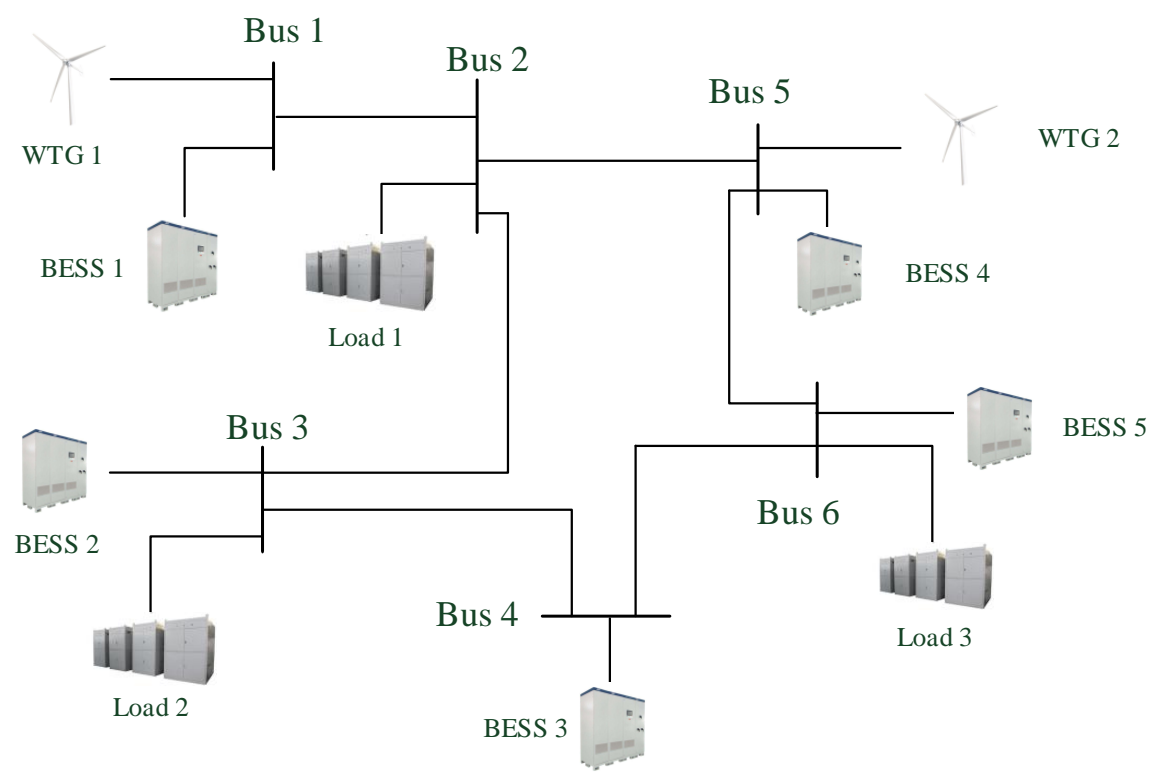

Figure 1. Islanded microgrid system.

The traditional solution of this situation is to use the Lagrange multiplier method, and the Lagrange function for the optimal problem can be constructed as:

$$
\mathcal{L}=\sum_{i \in N_{B}} C\left(P_{B E S S_{i}}\right)+\lambda\left(\sum_{i \in N_{L}} P_{L_{i}}-\sum_{i \in N_{R}} P_{R E S_{i}}\right)
$$

where $\lambda$ is the Lagrange multiplier associated with the equality constraint.

The Lagrangian operator $\mathcal{L}$ is minimized when the following equation is satisfied:

$$
\begin{aligned}
\frac{\partial \mathcal{L}}{\partial P_{B E S S_{i}}} & =\frac{\mathrm{d} C\left(P_{B E S S_{i}}\right)}{\mathrm{d} P_{B E S S_{i}}}-\lambda \\
& =a_{i} P_{B E S S_{i}}+b_{i}-\lambda \\
& =0
\end{aligned}
$$

which yields the following optimal solution:

$$
P_{B E S S_{i}}=\frac{\lambda-b_{i}}{a_{i}}
$$

Then, through substituting Equation (15) into Equation (10), the optimized incremental cost of each component can be represented as:

$$
\lambda=\frac{\sum_{i \in N_{L}} P_{L_{i}}-\sum_{i \in N_{R}} P_{R E S_{i}}+\sum_{i \in N_{B}} \frac{b_{i}}{a_{i}}}{\sum_{i \in N_{B}} \frac{1}{a_{i}}}
$$

Furthermore, considering of the generation constraints of each component, the optimal solution is given as [23]:

$$
\begin{cases}a_{i} P_{B E S S_{i}}+b_{i}=r^{*}, & P_{B E S S_{i}}^{\min }<P_{B E S S_{i}}<P_{B E S S_{i}}^{\max } \\ a_{i} P_{B E S S_{i}}+b_{i}<r^{*}, & P_{B E S S_{i}}=P_{B E S S_{i}}^{\max } \\ a_{i} P_{B E S S_{i}}+b_{i}>r^{*}, & P_{B E S S_{i}}=P_{B E S S_{i}}^{\min }\end{cases}
$$

where $r^{*}=\lambda$ is the optimal incremental cost. 
The above solution can be solved through the centralized control strategy. However, due to the timely communication and calculation manner, the centralized control strategy cannot provide the desired responses under unexpected and rapidly changed disturbances. In contrast, the distributed control strategy is flexible, scalable, reliable, and cost-effective to implementation, and it is wildly adopted to maintain system stability and provide optimal control performances.

With the theory of consensus algorithm, the optimal control problem can be solved by Equation (18):

$$
r_{i}[k+1]=\sum_{j \in N_{j}} w_{i j} r_{j}[k]
$$

where $r$ is the incremental cost.

Given that all the components are operating in a stable state at $t=0$, and following the consensus algorithm, the optimal incremental cost will converge to Equation (19) at $t=T$.

$$
r_{t=1 \cdot T}^{*}=\frac{\sum_{i \in N_{B}}\left(a_{i} P_{B E S S_{i}}+b_{i}\right)}{N}
$$

where $T$ is a convergent period to obtain the optimized incremental cost with a consensus algorithm.

However, as described in Equation (20), the result obtained by the consensus algorithm in one convergent period is not equal to that calculated by the Lagrange multiplier method with a centralized control strategy. That is to say, the supply-demand balance is broken. The supply-demand mismatch is described by Equation (21).

$$
\begin{gathered}
\lambda=\frac{\sum_{i \in N_{L}} P_{L_{i}}-\sum_{i \in N_{R}} P_{R E S_{i}}+\sum_{i \in N_{B}} \frac{b_{i}}{a_{i}}}{\sum_{i \in N_{B}} \frac{1}{a_{i}}} \\
=\frac{\sum_{i \in N_{B}} P_{B E S S_{i}}+\sum_{i \in N_{B}} \frac{b_{i}}{a_{i}}}{\sum_{i \in N_{B}} \frac{1}{a_{i}}} \neq \frac{\sum_{i \in N_{B}}\left(a_{i} P_{B E S S_{i}}+b_{i}\right)}{N}=r^{*} \\
\Delta P=\sum_{i \in N_{B}} P_{B E S S_{i}}^{\lambda}-\sum_{i \in N_{B}} P_{B E S S_{i}}^{r^{*}} \\
=\sum_{i \in N_{B}} \frac{1}{a_{i}} \cdot\left(\frac{\sum_{i \in N_{B}} P_{B E S S_{i}}^{\lambda}+\sum_{i \in N_{B}} \frac{b_{i}}{a_{i}}}{\sum_{i \in N_{B}} \frac{1}{a_{i}}}-b_{i}\right) \\
\quad-\sum_{i \in N_{B}} \frac{1}{a_{i}} \cdot\left(\frac{\sum_{i \in N_{B}}\left(a_{i} P_{B E S S_{i}}^{r^{*}}+b_{i}\right)}{N}-b_{i}\right) \\
\neq 0
\end{gathered}
$$

In order to deal with the above problem, an improved distributed approach was proposed by [14], and the updating rule for the leader agent follows:

$$
r_{i}[k+1]=\sum_{j \in N_{j}} w_{i j} r_{j}[k]+\varepsilon \cdot \Delta P[k]
$$

where $\varepsilon$ is the convergence coefficient, which controls the convergence speed of the leader agent.

Then, [16] modified the updating rules for agents coordination, which are represented as:

$$
\left\{\begin{aligned}
r_{i}[k+1] & =\sum_{j \in N_{j}} w_{i j} r_{j}[k]+\varepsilon \cdot \Delta P_{i}[k] \\
P_{B E S S_{i}}[k+1] & =\frac{r_{i}[k+1]-b_{i}}{a_{i}} \\
\Delta P_{i}[k+1] & =\sum_{j \in N_{j}} w_{i j} \cdot\left(\Delta P_{i}[k]+\left(P_{B E S S_{i}}[k+1]-P_{B E S S_{i}}[k]\right)\right)
\end{aligned}\right.
$$


In the initial state, $\Delta P_{t=0 \cdot T}[0]=0$. After completing one convergent period, $\Delta P_{t=1 \cdot T}[0] \neq 0$, then $\varepsilon$ works to eliminate the supply-demand mismatch until $\Delta P_{t=n \cdot T}[0]=0$. As is shown in Equation (24), the optimal incremental cost converges to that calculated by central control strategy.

$$
\begin{aligned}
\lambda & =\frac{\sum_{i \in N_{B}} P_{B E S S_{i}}+\sum_{i \in N_{B}} \frac{b_{i}}{a_{i}}}{\sum_{i \in N_{B}} \frac{1}{a_{i}}} \\
& =\frac{\sum_{i \in N_{B E S S_{i}}}\left(a_{i} P_{B_{E S S_{i}}}+b_{i}\right)}{N} \\
& =r^{*}
\end{aligned}
$$

\section{Proposed Distributed Optimal Control of BESS with Fast Frequency Recovery}

Through the distributed control strategy introduced in Section 3, the optimal incremental cost can converge to the desired value after $n T s$, which produces negative effects on system stability. Furthermore, the authors also find that the frequency recovery process will take a long time, or even have deviation following great and rapid changes of the wind turbine generator's (WTG's) output power and load demand. This may result in a system crash. To overcome this problem, this paper proposes a novel distributed optimal control of BESSs to realize fast frequency recovery and enhance system stability.

\subsection{Distributed Optimal Control Strategy}

The system control structure of $[14,16]$ is described in Figure 2, and the proposed control structure is described in Figure 3. System power-frequency characteristic is described by $\frac{\Delta P}{\Delta f}=\frac{1}{M s+D}$. Most previous studies in the literature have focused on modifying the updating rule of the consensus algorithm for optimization. However, it still cannot greatly guarantee the frequency stability. This study designed a supplementary controller to enhance the frequency stability, which is shown in Figure 3. The deviation of frequency $\Delta f$ is regarded as the controlled variable, and the control signal is regarded as the referential deviation of supply-demand mismatch $\Delta P^{r e f}[0]$. Based on this improvement, the deviation of frequency $\Delta f$ is thoroughly eliminated and the frequency recovery process is also accelerated.

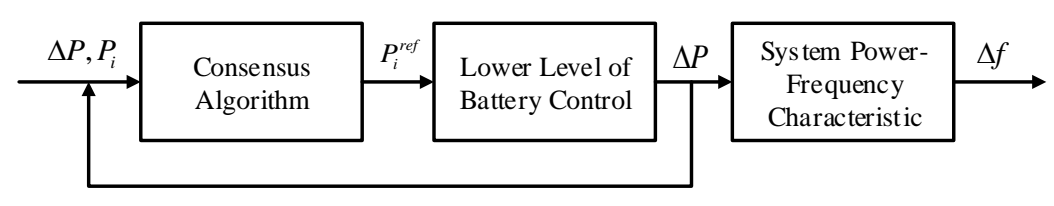

Figure 2. System control process.

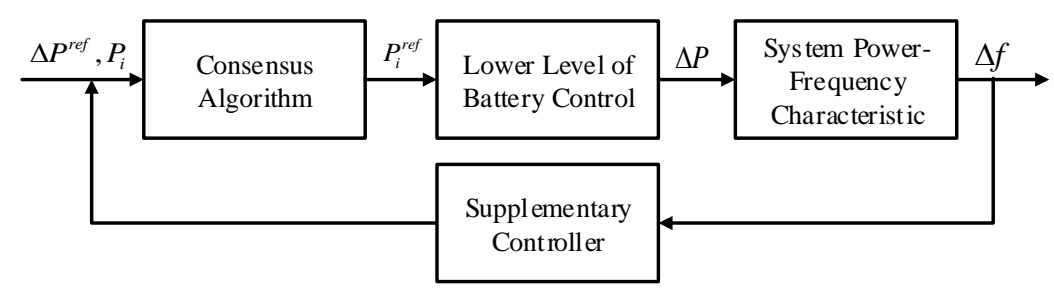

Figure 3. Proposed system control process.

This paper employs ILADRC algorithm. Recently, the LADRC algorithm, which was developed from the PID algorithm, is widely employed in power system control and other fields. It inherits the essence of PID algorithm and removes its shortcoming. Furthermore, the LESO can well estimate system external and internal disturbance. It is obvious that the intermittent and random power of renewable energy sources is the external disturbance of microgrid. So, the BESSs in an islanded 
microgrid system can provide better control based on the LADRC to compensate for the fluctuation of system supply-demand mismatch. That is to say, the stability of microgrid frequency can be greatly enhanced. Furthermore, the effectiveness of ILADRC has proved better than the LADRC. Consequently, the ILADRC has great anti-disturbance capability and robustness. This is also the main reason that the ILADRC is employed in this paper. Moreover, the parameter tuning process of the ILADRC-based controller is much easier than that of controllers based on other control algorithms. Moreover, the ILADRC-based controller is independent of an accurate system model, which means that a complex modeling process can be avoided.

\subsection{Algorithm Implementation}

With the proposed control strategy, the construction of the leader agent and normal agent are shown in Figures 4 and 5, respectively. And Figure 6 shows the communication relationship of BESSs. Firstly, the normal agent measures the component output power and initializes the value of $r_{i}[0]$. Then, the communication signal of $\Delta P_{i}[k]$ and $r_{i}[k]$ can be obtained through the updating rules described in Equation (23). Different from the normal agent, the leader agent still has to measure the value of system frequency and calculate the deviation of frequency $\Delta f$ for initialization. Through the consensus algorithm, the referential power output of each component can be calculated by the optimized incremental cost $r^{*}$.

After obtaining the referential power of each BESS, it will be controlled by the lower-level control block, as is shown in Figure 7. Considering the sampling process and time-delay characteristic, the transfer function of the decoupled d axis current loop is described in Figure 8. Furthermore, the transfer function can be equivalent to the inertial unit, and the inertia time constant is equal to $3 T_{s}$. The agent of $B E S S_{1}$ is the leader agent, and the agents of others are the normal agents. Furthermore, the variable-speed WTG model [21] is described in Figure 9; its principles and parameter values will not be introduced in this paper.

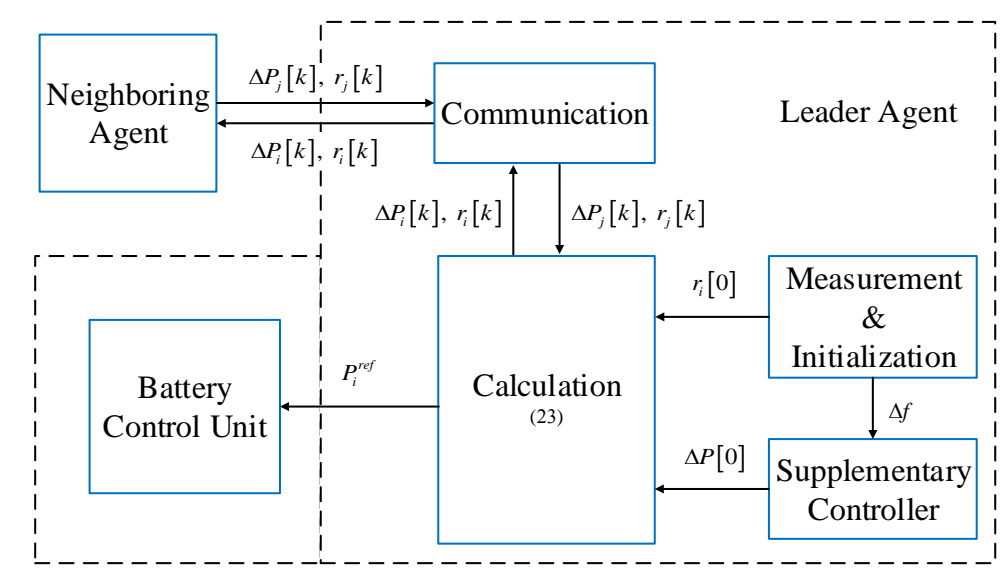

Figure 4. Leader agent block.

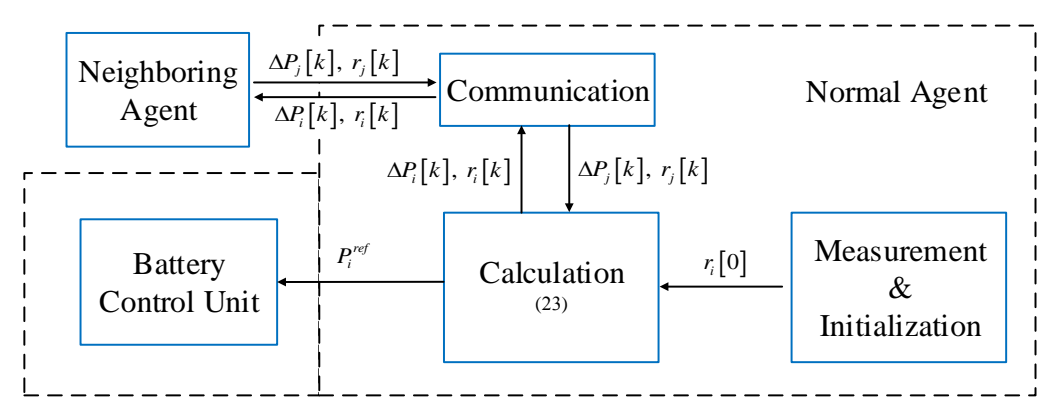

Figure 5. Normal agent block. 


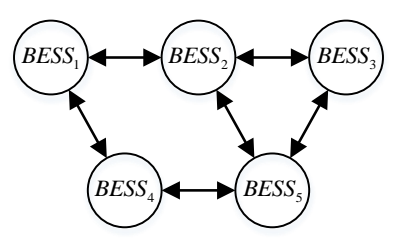

Figure 6. Node of BESSs.

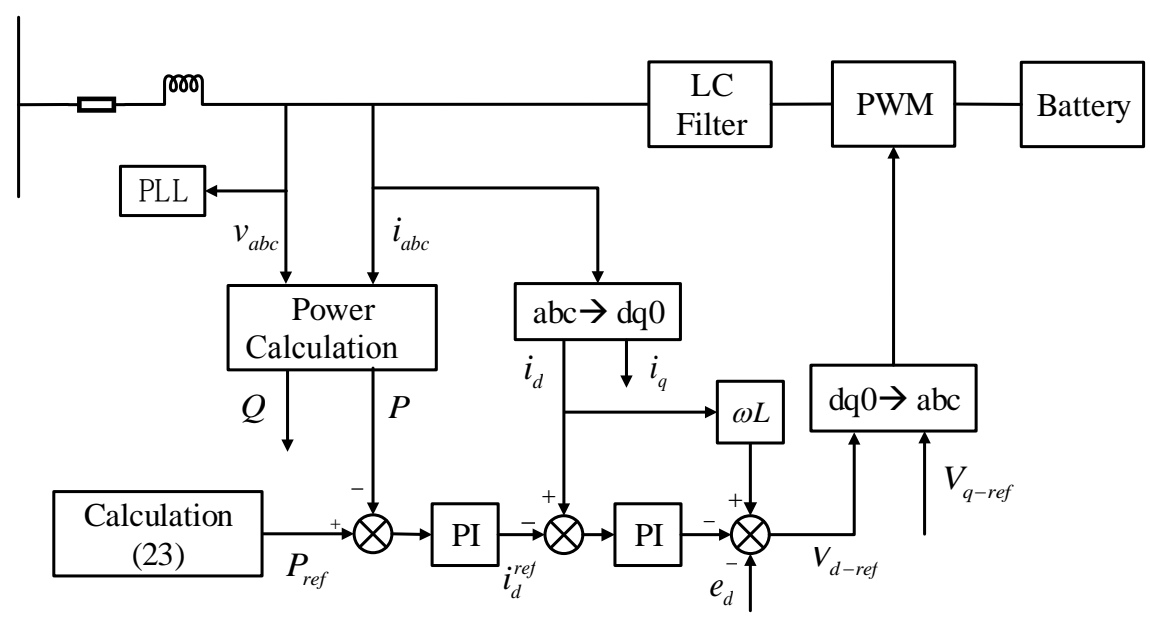

Figure 7. Power control block of BESS.

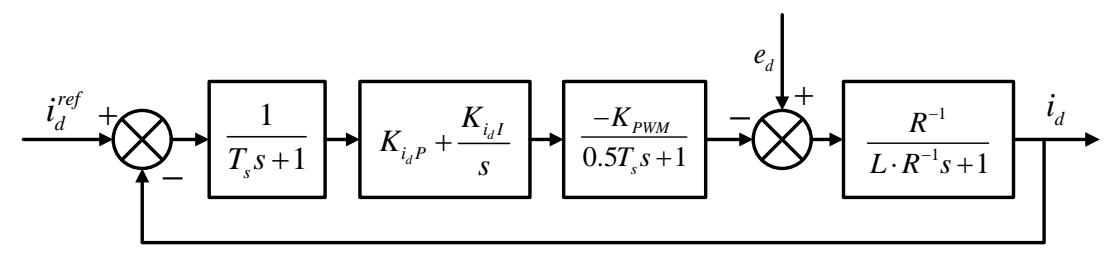

Figure 8. Transfer function of BESS.

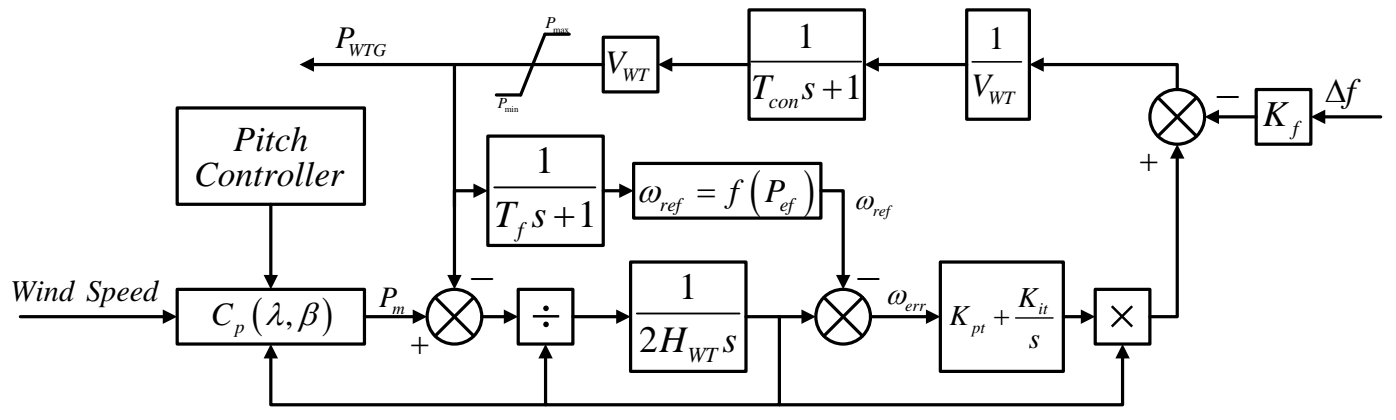

Figure 9. Simulation model of wind turbine generator.

The proposed control strategy of a microgrid is shown in Figure 10. The imaginary lines represent the communication topology. The referential power output of each BESS can be obtained through communicating with its neighboring agent.

Numerical simulations with the aforementioned control strategy under different operation conditions were tested with the above model, and the results are described in Section 5. Then, the validity of the proposed method is demonstrated through comparison to previous literatures in the following section. 


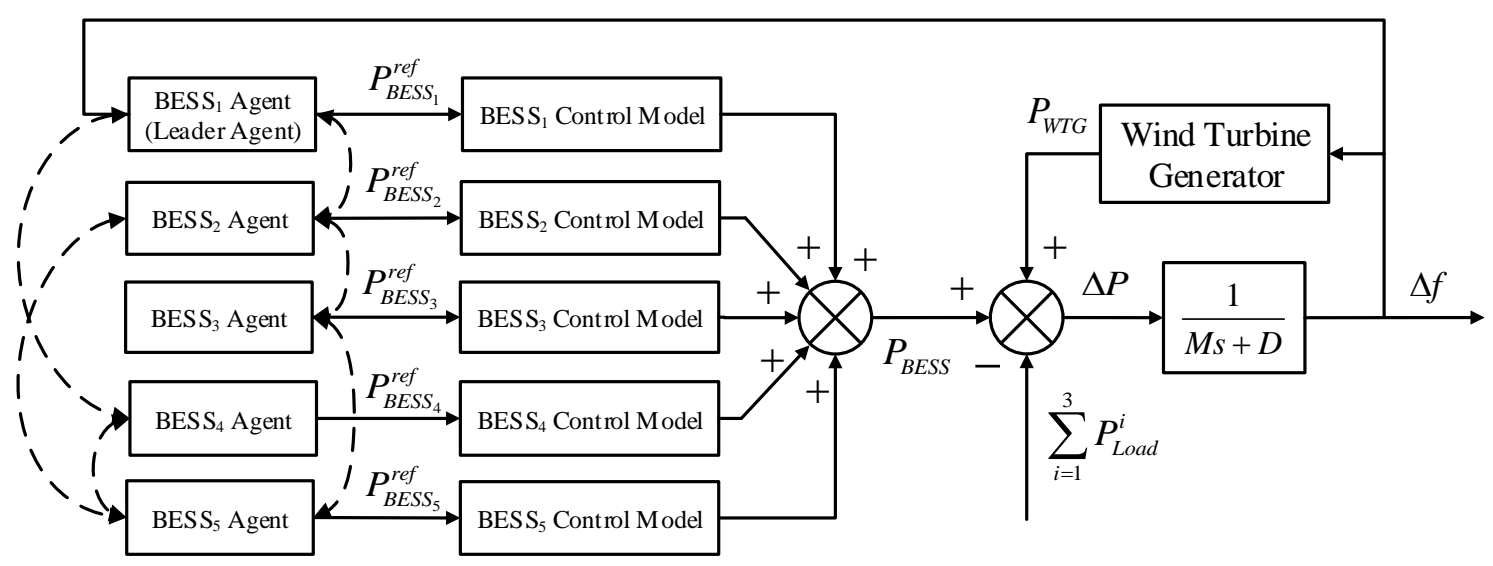

Figure 10. The proposed control strategy of the microgrid.

\section{Simulation Results and Analysis}

The simulation results are described in this section and the simulations are testing in an islanded microgrid with a configuration of five BESSs, two WTGs, and three load demands. The parameters of the BESS are summarized in Table 1, and the parameters of the WTG and load demand are summarized in Table 2. The wind turbine generator used in this work is the doubly-fed induction generator, which will not be introduced in detail in this paper. The supplementary controller parameters are shown in Table 3. All the simulations are testing in MATLAB/Simulink and the step time is $0.01 \mathrm{~s}$.

Table 1. Simulation parameters of BESS.

\begin{tabular}{|c|c|c|c|c|c|}
\hline BESS & $a_{i}$ & $b_{i}$ & $P_{B E S S_{i}}^{\min }$ (p.u.) & $P_{B E S S_{i}}^{\max }$ (p.u.) & Initial Value (p.u.) \\
\hline$B E S S_{1}$ & 0.83 & 0.007 & 0 & 0.35 & 0.15 \\
\hline$B E S S_{2}$ & 0.79 & 0.006 & 0 & 0.40 & 0.10 \\
\hline$B E S S_{3}$ & 0.90 & 0.009 & 0 & 0.30 & 0.12 \\
\hline$B E S S_{4}$ & 0.93 & 0.012 & 0 & 0.25 & 0.13 \\
\hline$B E S S_{5}$ & 0.78 & 0.008 & 0 & 0.30 & 0.05 \\
\hline
\end{tabular}

Table 2. Simulation parameters of load demand and wind turbine generator (WTG).

\begin{tabular}{|c|c|c|c|}
\hline Load and WTG & Initial Value (p.u.) & $P_{i}^{\min }$ (p.u.) & $P_{i}^{\max }$ (p.u.) \\
\hline $\operatorname{Load}_{1}$ & 0.40 & 0 & 0.60 \\
\hline $\mathrm{Load}_{2}$ & 0.30 & 0 & 0.50 \\
\hline $\mathrm{Load}_{3}$ & 0.30 & 0 & 0.60 \\
\hline$W T G_{1}$ & 0.25 & 0 & 0.50 \\
\hline$W T G_{2}$ & 0.20 & 0 & 0.60 \\
\hline
\end{tabular}

Table 3. Simulation parameters of the ILADRC-based controller.

\begin{tabular}{ccc}
\hline$b_{0}$ & $\omega_{\boldsymbol{o}}$ & $\omega_{\boldsymbol{c}}$ \\
\hline 5.172 & 1.101 & 10.241 \\
\hline
\end{tabular}

Furthermore, this study adopted the rate of change of frequency $(R o C o F)$ and the integral of time-weighted absolute value of the error (ITAE) to be the evaluation indexes of system frequency stability. The RoCoF and ITAE are described by Equations (25) and (26), respectively.

$$
\text { RoCoF }=\int t\left|\frac{d f}{d t}\right| d t
$$




$$
\operatorname{ITAE}=\int t|\Delta f| d t
$$

\subsection{Case A}

In this case, performances of the proposed method at initial state are investigated. The initial power output of BESSs are shown in Table 1. The fluctuation of supply-demand and WTG power output are supposed to be stable and their initial values are shown in Table 2. The response of total active power deviation and microgrid frequency deviation are described in Figure 11. As is shown in Figure 11, the frequency based on the proposed distributed strategy can be recovered to its normal value in $2.7 \mathrm{~s}$. And the overshoot of frequency is $0.0006 \mathrm{~Hz}$, it's better than those derived by other methods. The detailed comparison results are shown in Table 4. Obviously, microgrid system with the proposed distributed strategy has better frequency recovery capability and desired optimal performances. The convergence curve of incremental cost is described in Figure 12 and the active power of each BESS is shown in Figure 13.

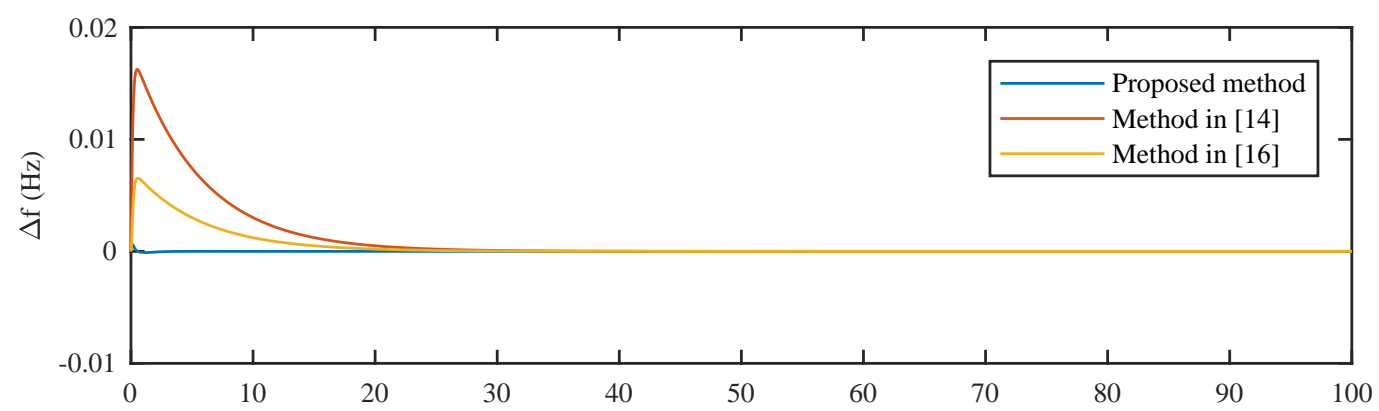

(a) Time (s)

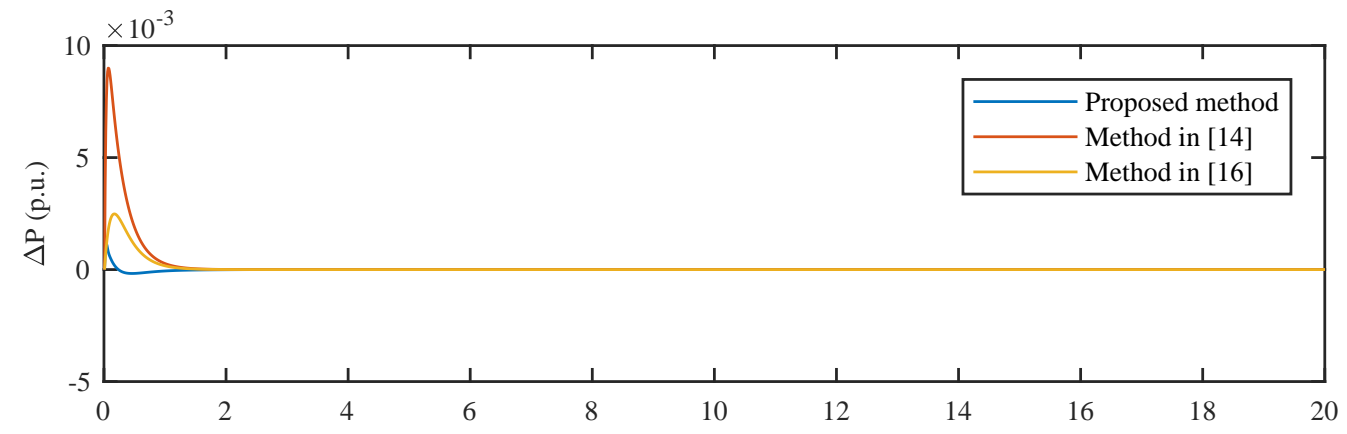

(b) Time (s)

Figure 11. System transient response. (a) Microgrid frequency deviation. (b) Total power deviation.

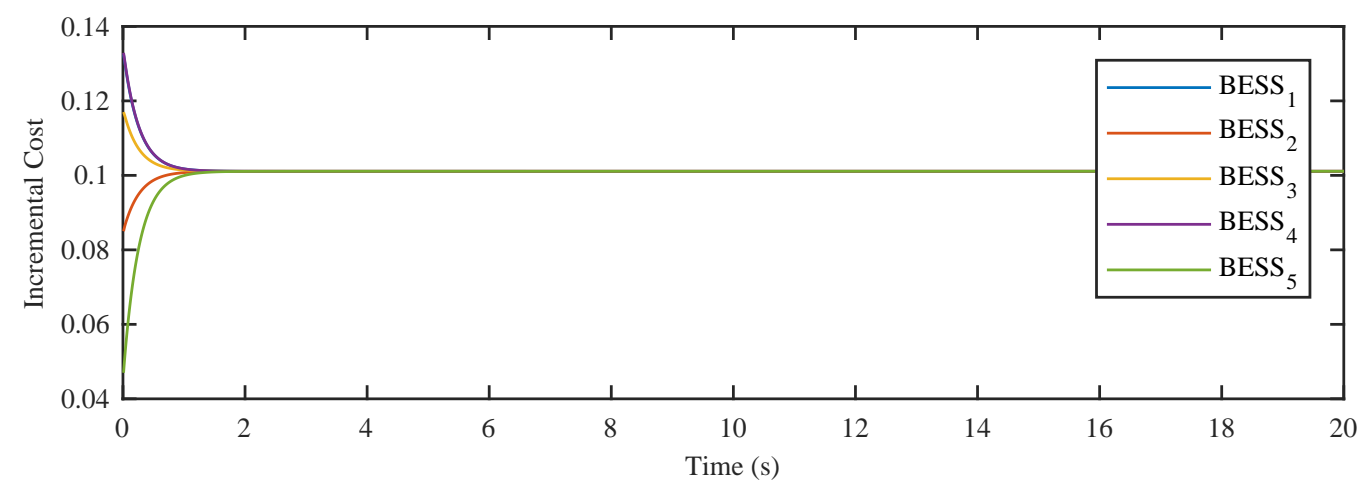

Figure 12. Convergence curve of incremental cost. 


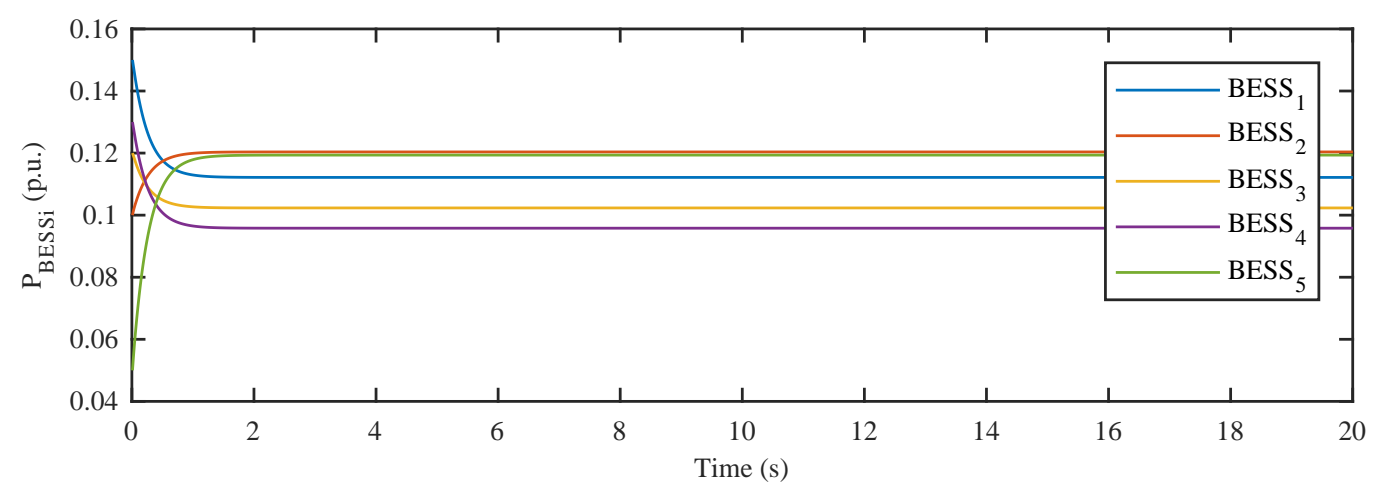

Figure 13. Power output of BESSs.

Table 4. Performance comparison from the initial state.

\begin{tabular}{lccc}
\hline Control Strategy & Overshoot & ITAE & RoCoF \\
\hline Proposed method & $-0.0006 \mathrm{~Hz}$ & 0.0012 & 0.0013 \\
Method in [16] & $-0.0070 \mathrm{~Hz}$ & 0.9232 & 0.0877 \\
Method in [14] & $-0.0174 \mathrm{~Hz}$ & 2.2521 & 0.2152 \\
\hline
\end{tabular}

\subsection{Case $B$}

The validity of the proposed method in handling the situation with unpredicted fluctuation of load demand is demonstrated. Suppose that WTG power is stable, and the load demand suddenly increases from 1.0 p.u. to 1.1 p.u. at $10 \mathrm{~s}$. The total active power deviation can be well eliminated by all three distributed control strategies, as is shown in Figure 14b.

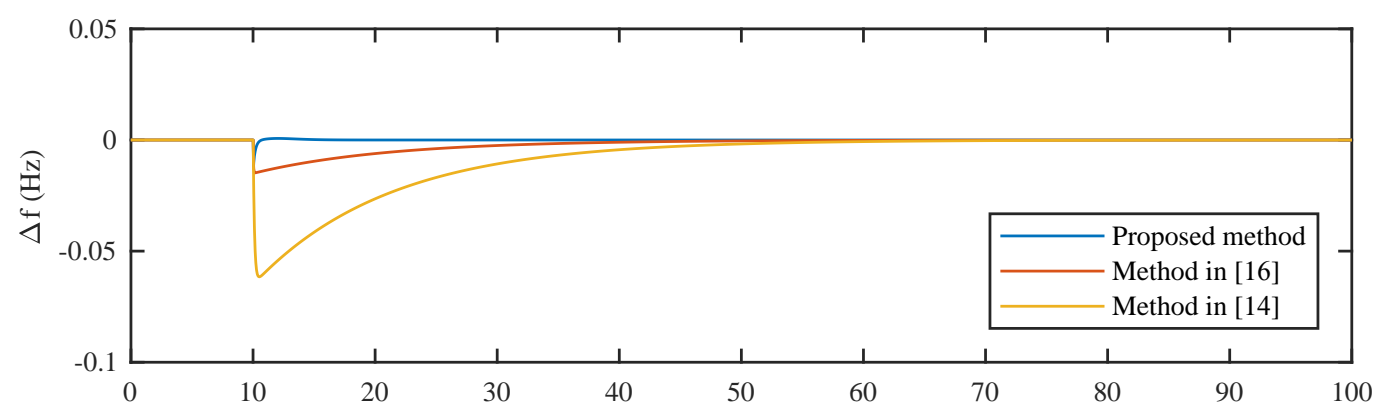

(a) Time (s)

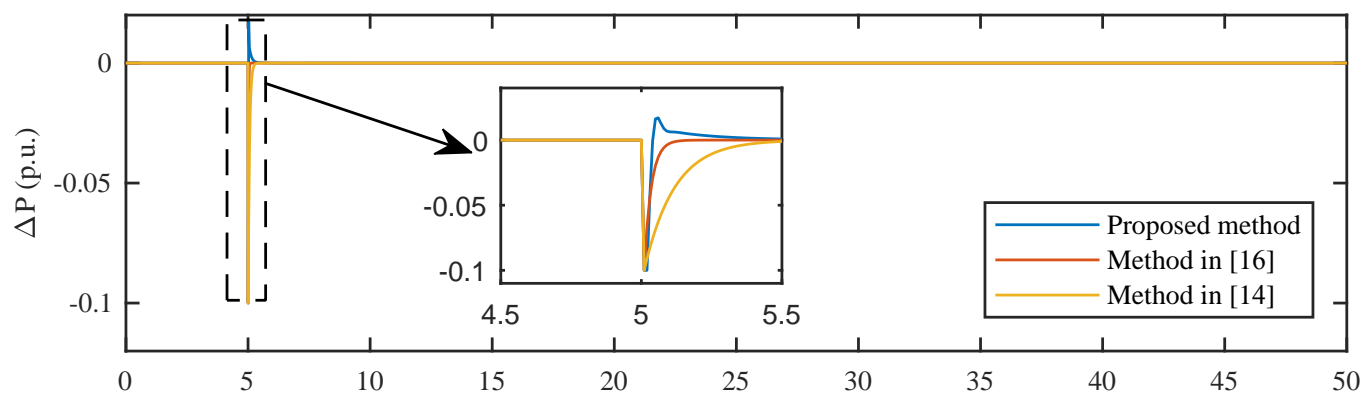

(b) Time (s)

Figure 14. System transient response. (a) Microgrid frequency deviation. (b) Total power deviation.

However, the overshoot of frequency based on the proposed control strategy is $0.0115 \mathrm{~Hz}$, which is smaller than $0.0617 \mathrm{~Hz}$ and $0.0148 \mathrm{~Hz}$ obtained through the methods in [14,16], respectively. 
Additionally, the settling time of the system frequency with the proposed control strategy, which is $4.9 \mathrm{~s}$, is shorter than that based on the other methods. The convergence curve of incremental cost and the power of BESSs are described in Figures 15 and 16, respectively. Simulation results in Table 5 indicate the significant importance of the supplementary controller with the ILADRC algorithm. The supplementary controller can compensate for the deviation of frequency faster, and the incremental cost of the BESSs can also converge to the optimization value simultaneously.

Table 5. Performance comparison with +0.1 p.u. load demand change.

\begin{tabular}{lccc}
\hline Control Strategy & Overshoot & ITAE & RoCoF \\
\hline Proposed method & $-0.0115 \mathrm{~Hz}$ & 0.0074 & 0.0070 \\
Method in [16] & $-0.0148 \mathrm{~Hz}$ & 1.8601 & 0.1721 \\
Method in [14] & $-0.0617 \mathrm{~Hz}$ & 8.1005 & 0.7325 \\
\hline
\end{tabular}

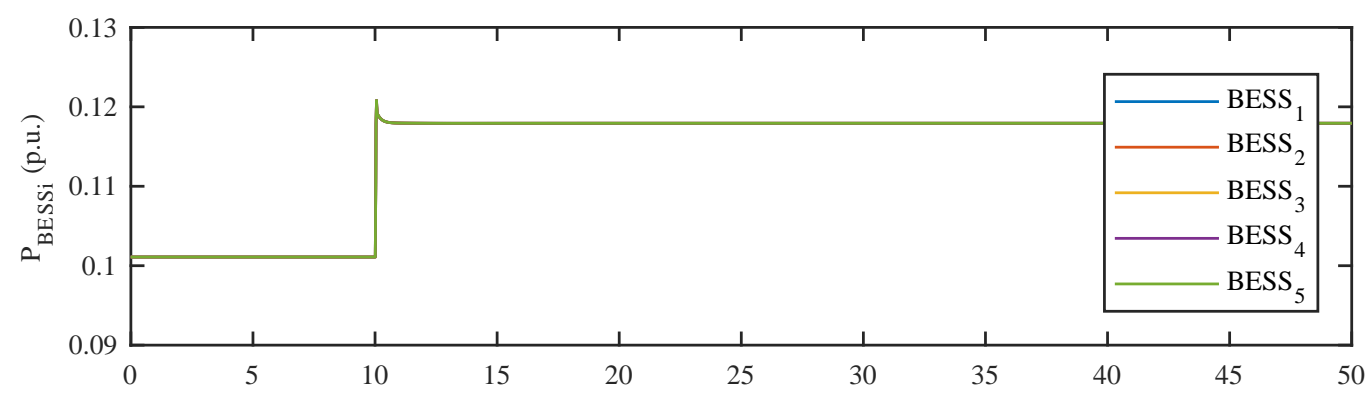

(a) Time (s)
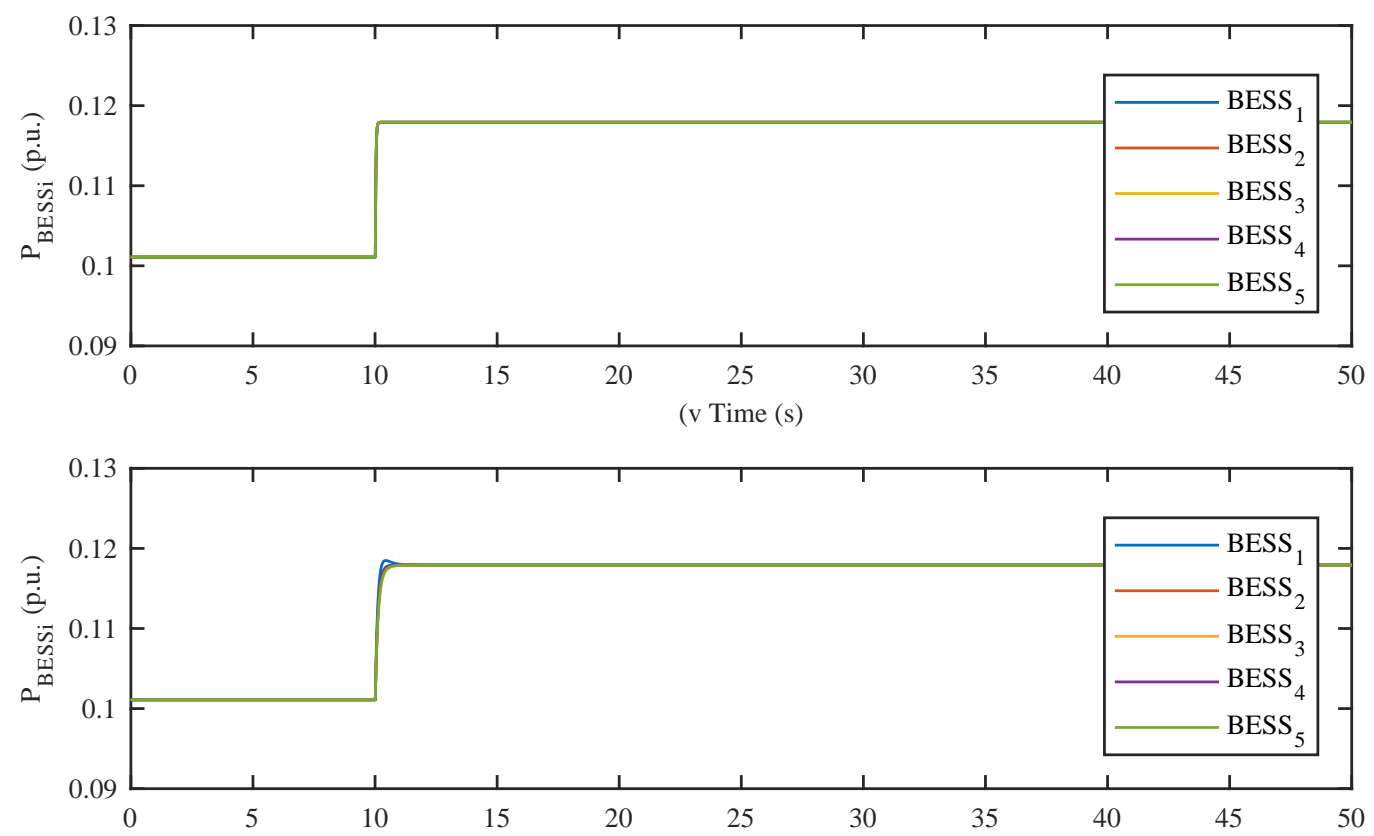

(c) Time (s)

Figure 15. Convergence curve of incremental cost. (a) Convergence of incremental cost with the proposed method. (b) Convergence of incremental cost with the method in [16]. (c) Convergence of incremental cost with the method in [14]. 


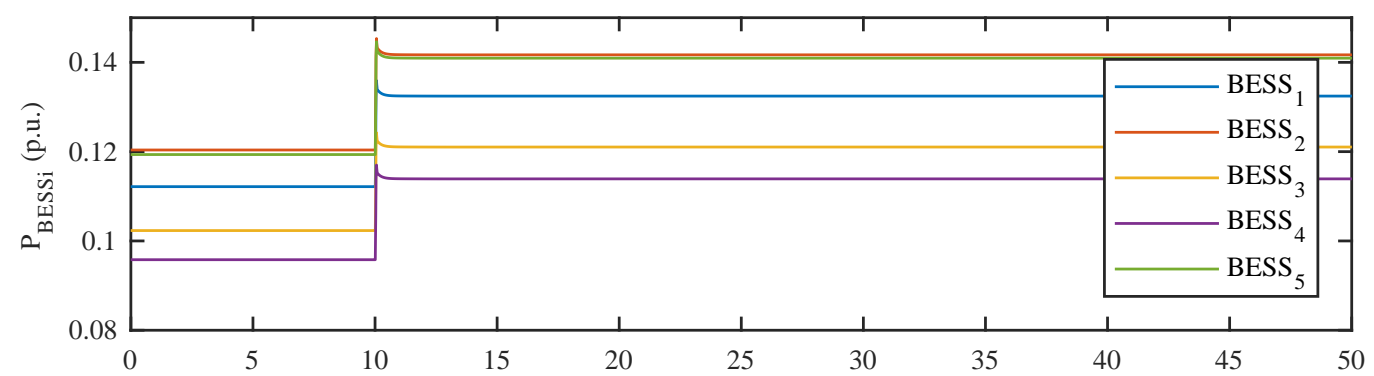

(a) Time (s)

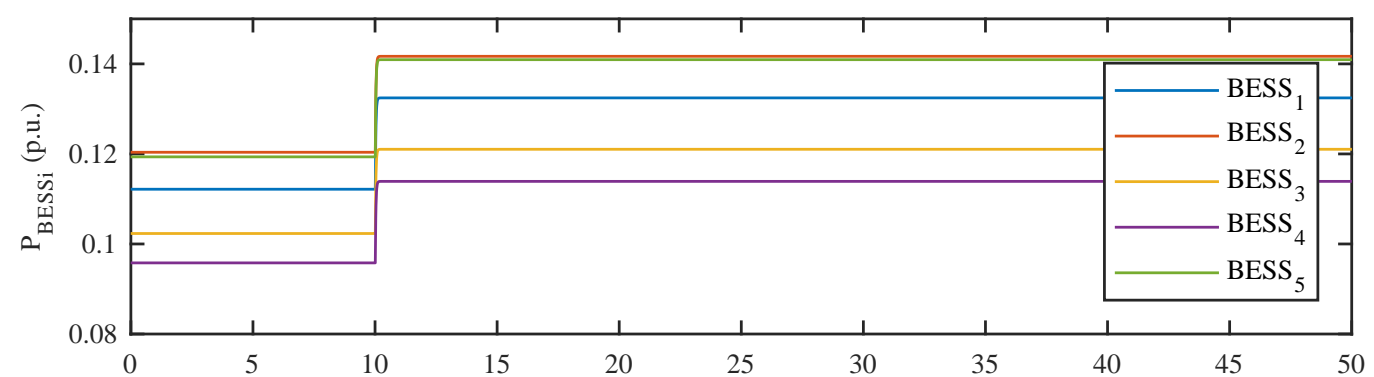

(b) Time (s)

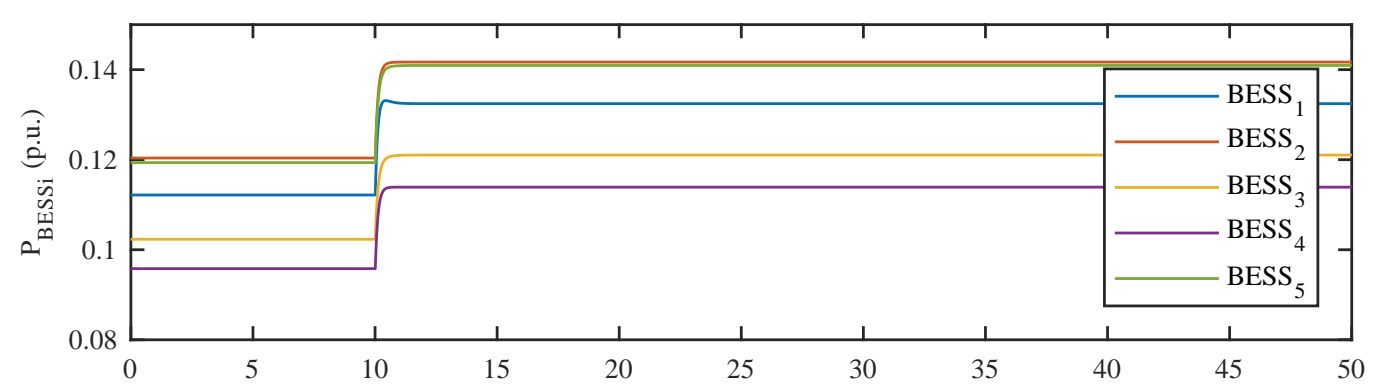

(c) Time (s)

Figure 16. Power of the BESSs. (a) Power of the BESSs with the proposed method. (b) Power of the BESSs with the method in [16]. (c) Power of the BESSs with the method in [14].

\subsection{Case C}

In the practical environment, unpredictable disturbances cannot be neglected anymore. Then, the anti-disturbance ability of the distributed optimal control strategy is of significant importance. So, the system performances under stochastic power output of the WTGs are investigated. The total load demand is supposed to be stable at 1.0 p.u.

The stochastic characteristic of wind power is shown in Figure 17. The comparison results of supply-demand mismatch and frequency deviation are described in Figure 18. From comparison results shown in Table 6, it can be found that frequency fluctuation with the proposed method is in an extremely smaller range than that based on other methods, which demonstrates the superior anti-disturbance capability of the proposed method. The power of the BESSs and the convergence curve of incremental cost are shown in Figures 19 and 20, respectively.

Table 6. Performances with stochastic disturbance of WTG.

\begin{tabular}{lccc}
\hline Control Strategy & ITAE & RoCoF & Range of $\boldsymbol{\Delta f}$ \\
\hline Proposed method & 0.1760 & 0.2955 & $-1.25 \times 10^{-4} \mathrm{~Hz} \sim 1.13 \times 10^{-4} \mathrm{~Hz}$ \\
Method in [16] & 1.1805 & 1.2697 & $-6.55 \times 10^{-4} \mathrm{~Hz} \sim 7.74 \times 10^{-4} \mathrm{~Hz}$ \\
Method in [14] & 3.9578 & 3.9021 & $-2.43 \times 10^{-3} \mathrm{~Hz} \sim 2.74 \times 10^{-3} \mathrm{~Hz}$ \\
\hline
\end{tabular}




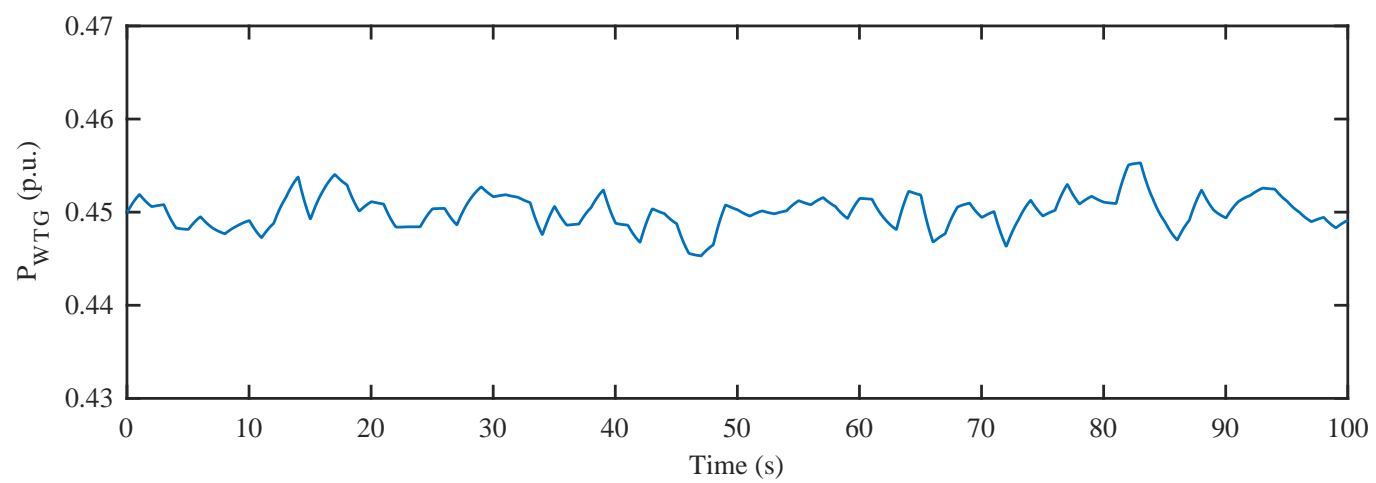

Figure 17. The total stochastic power output of the WTG.

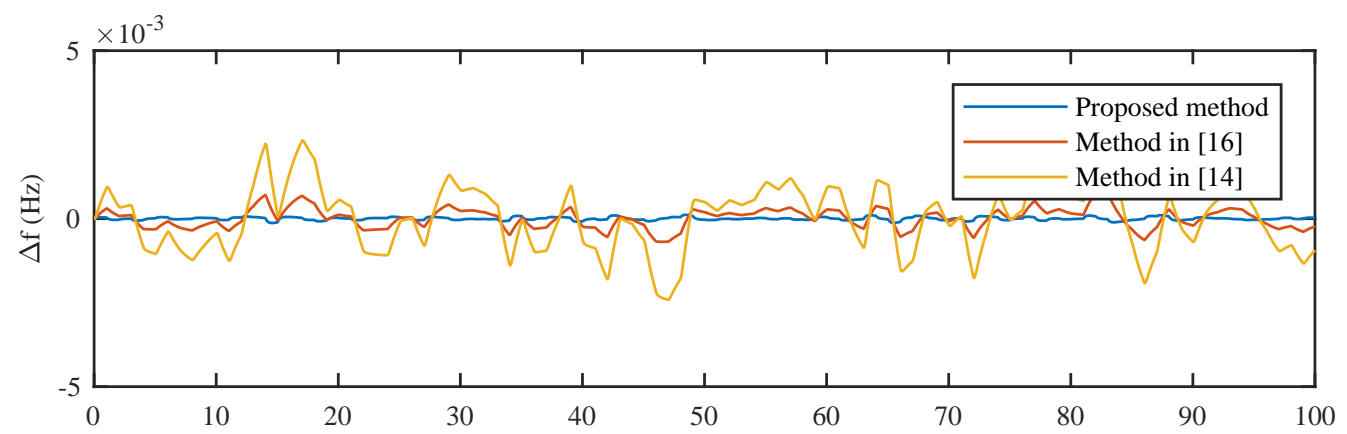

(a) Time (s)

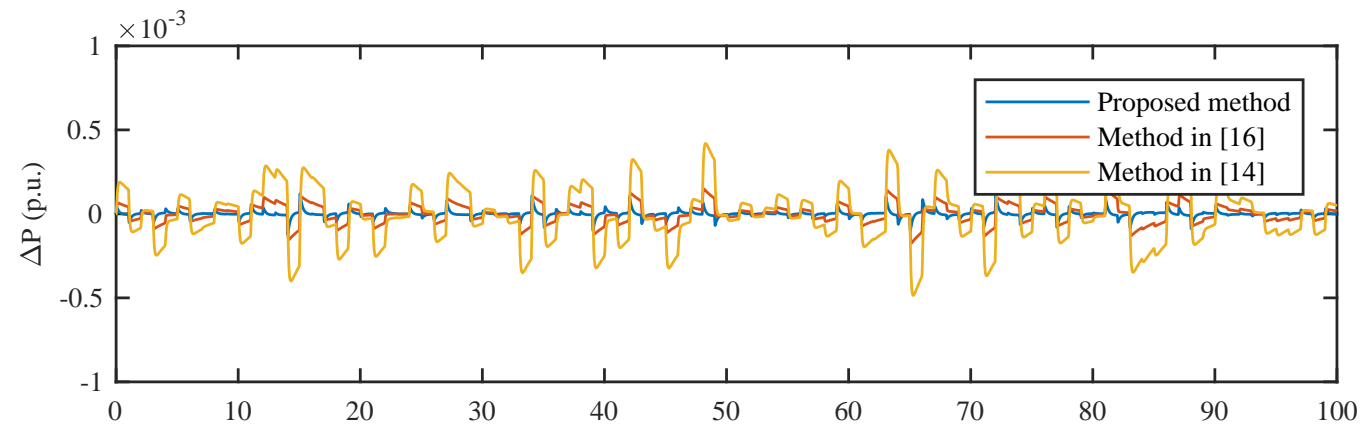

(b) Time (s)

Figure 18. System transient response. (a) Microgrid frequency deviation. (b) Total power deviation.

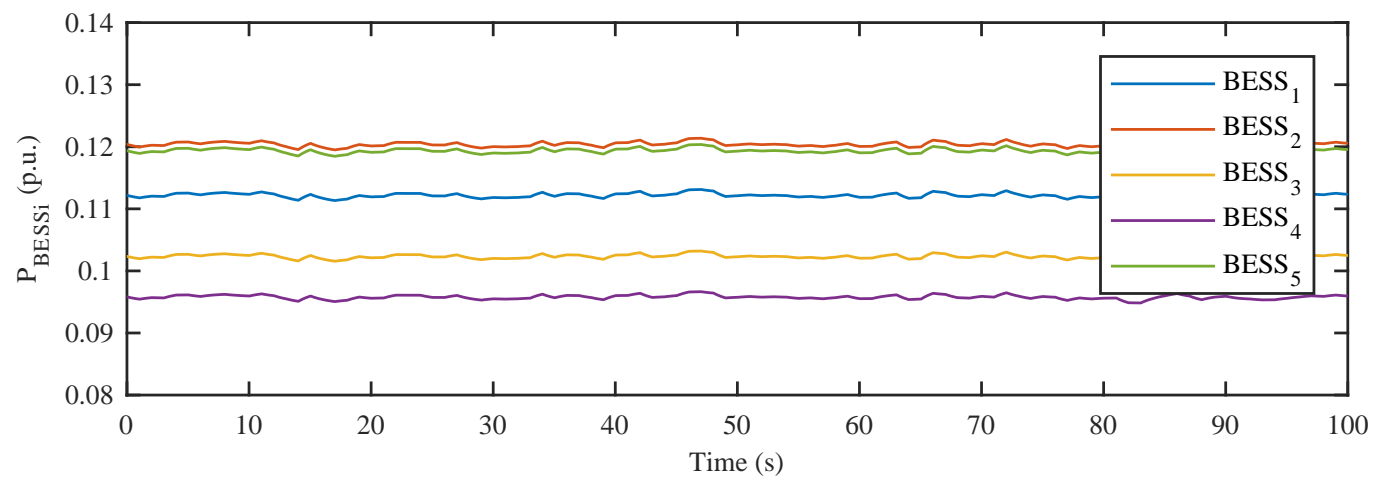

Figure 19. Power output of the BESSs. 


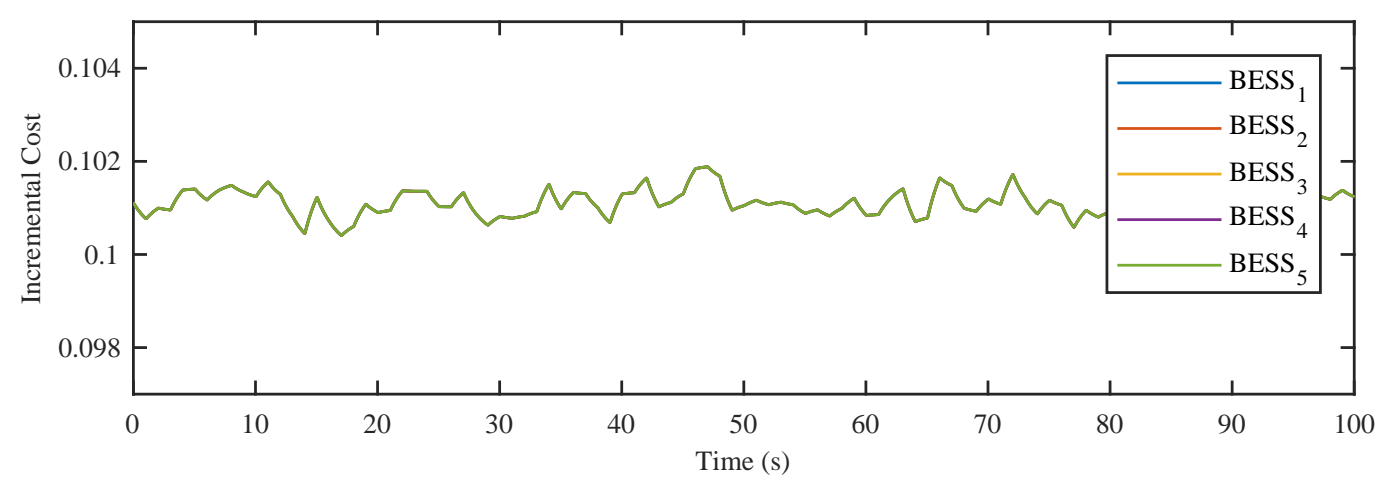

Figure 20. Convergence curve of incremental cost.

\section{Conclusions}

In an islanded microgrid, the system frequency changes more rapidly and sharply than that in a traditional power grid while supply-demand mismatch occurs. Therefore, this paper proposes a novel distributed optimal control strategy of BESSs in an islanded microgrid, which can provide optimal control performances and simultaneously realize faster frequency recovery, compared with previous studies. A multi-agent system based on the consensus algorithm is adopted in the proposed control strategy. A supplementary controller based on the ILADRC algorithm is employed to greatly enhance the frequency stability. The validity of the proposed distributed strategy is demonstrated by adequate simulation experiments, comparing the proposed method with two previous methods.

On the one hand, the proposed control strategy realizes the maximum welfare of the BESSs in a microgrid, so it makes economic sense. On the other hand, practically, the proposed method guarantees the microgrid stability while the components are operating at minimum cost, which ensures system security and consumers' experience. Based on the above aspects, this work realizes the economic operation of a microgrid without reducing power quality, and it even greatly enhances system stability.

In future work, the proposed distributed optimal control strategy can be improved for a system with more realistic constraints. Furthermore, it also has the potential to solve multi-microgrid optimal control problem.

Author Contributions: Conceptualization, X.Q.; Data curation, X.Q.; Formal analysis, X.Q., G.Z. and Z.W.; Funding acquisition, X.Q., H.L., G.Z. and Z.W.; Investigation, X.Q., Y.B., H.L., Y.Z., G.Z. and Z.W.; Methodology, X.Q. and Y.B.; Project administration, X.Q.; Resources, X.Q. and Y.Z.; Software, X.Q.; Supervision, X.Q., Y.B. and H.L.; Validation, X.Q.; Visualization, X.Q.; Writing—original draft, X.Q.; Writing-review \& editing, X.Q., Y.B., H.L. and Y.Z.

Funding: This research was funded by National Key R\&D Program of China, grant number [NO.2017YFB0902100].

Conflicts of Interest: The authors declare no conflict of interest.

\section{Abbreviations and Notations}

$\begin{array}{ll}\text { CERTS } & \text { Consortium for Electric Reliability Technology Solutions } \\ \text { RESs } & \text { Renewable Energy Sources } \\ \text { BESSs } & \text { Battery Energy Storage Systems } \\ \text { WTG } & \text { Wind Turbine Generator } \\ \text { MAS } & \text { Multi-Agent System } \\ \text { LADRC } & \text { Linear Active Disturbance Rejection Control } \\ \text { LESO } & \text { Linear Extended State Observer } \\ W & \text { Weight matrix } \\ f & \text { System total disturbance of external and internal disturbance } \\ x_{i} & \text { System states } \\ z_{i} & \text { Estimation of system states }\end{array}$




\begin{tabular}{|c|c|}
\hline$\beta_{i}$ & Parameters of LESO \\
\hline$b_{0}, \omega_{0}, \omega_{c}, k_{p}, k_{d}$ & Controller parameters of LADRC \\
\hline$P_{B E S S_{i}}$ & Power output of the ith BESS \\
\hline$P_{R_{E S}}$ & Power output of the ith RES \\
\hline$P_{L_{i}}$ & Power output of the ith load \\
\hline$C\left(P_{B E S S_{i}}\right)$ & Cost of the ith BESS \\
\hline$a_{i}, b_{i}$ & Cost coefficients \\
\hline$N_{B}, N_{R}, N_{L}$ & The index sets of BESSs, RESs, and load demand \\
\hline$P_{B E S S_{i}}{ }^{\min } P_{B E S S_{i}}^{\max }$ & The lower and upper bounds of $i t h$ BESS power output \\
\hline $\mathcal{L}$ & Lagrange function \\
\hline$\lambda$ & Lagrange multiplier \\
\hline$r_{i}$ & Incremental cost of the ith BESS \\
\hline$r^{*}$ & Optimal incremental cost \\
\hline$\varepsilon$ & Convergence coefficient \\
\hline$\Delta P[k]$ & Supply-demand mismatch of $k t h$ iteration \\
\hline RoCoF & Rate of change of frequency \\
\hline ITAE & Integral of time-weighted absolute value of the error \\
\hline
\end{tabular}

\section{References}

1. Lasseter, R.H. Microgrids. In Proceedings of the Power Engineering Society Winter Meeting, New York, NY, USA, 27-31 January 2002. [CrossRef]

2. Abu-Sharkh, S.; Arnold, R.J.; Kohler, J.; Li, R.; Markvart, T.; Ross, J.N.; Steemers, K.; Wilson, P.; Yao, R. Can microgrids make a major contribution to UK energy supply? Renew. Sust. Energy Rev. 2006, 10, 78-127. [CrossRef]

3. Alsaidan, I.; Alanazi, A.; Gao, W.Z.; Wu, H.Y.; Khodaei, A. State-Of-The-Art in Microgrid-Integrated Distributed Energy Storage Sizing. Energies 2017, 10, 1421. [CrossRef]

4. Aditya, S.; Das, D. Application of battery energy storage system to load frequency control of an isolated power system. Int. J. Energy Res. 1999, 23, 247-258. [CrossRef]

5. Li, X.J.; Hui, D.; Lai, X.K. Battery energy storage station (BESS)-based smoothing control of photovoltaic (PV) and wind power generation fluctuations. IEEE Trans. Sustain. Energy 2013, 4, 464-473. [CrossRef]

6. He, G.N.; Chen, Q.X.; Kang, C.Q.; Xia, Q.; Poolla, K. Cooperation of wind power and battery storage to provide frequency regulation in power markets. IEEE Trans. Power Syst. 2017, 32, 3559-3568. [CrossRef]

7. Dreidy, M.; Mokhlis, H.; Mekhilef, S. Inertia response and frequency control techniques for renewable energy sources: A review. Renew. Sust. Energ. Rev. 2017, 69, 144-155. [CrossRef]

8. Yoldas, Y.; Onen, A.; Muyeen, S.M.; Vasilakos, A.V.; Alan, I. Enhancing smart grid with microgrids: Challenges and opportunities. Renew. Sust. Energ. Rev. 2017, 72, 205-214. [CrossRef]

9. Tsikalakis, A.G.; Hatziargyriou, N.D. Centralized control for optimizing microgrids operation. IEEE Trans. Energy Convers. 2008, 23, 241-248. [CrossRef]

10. Tan, K.T.; Peng, X.Y.; So, P.L.; Chu, Y.C.; Chen, M.Z.Q. Centralized control for parallel operation of distributed generation inverters in microgrids. IEEE Trans. Smart Grid 2012, 3, 1977-1987. [CrossRef]

11. Delille, G.; Francois, B.; Malarange, G. Dynamic Frequency Control Support by Energy Storage to Reduce the Impact of Wind and Solar Generation on Isolated Power System's Inertia. IEEE Trans. Sustain. Energy 2012, 3, 931-939. [CrossRef]

12. Abo-Khalil, A.G.; Lee, D.C. MPPT Control of Wind Generation Systems Based on Estimated Wind Speed Using SVR. IEEE Trans. Ind. Electron. 2008, 55, 1489-1490. [CrossRef]

13. Zhao, T.; Ding, Z. Cooperative Optimal Control of Battery Energy Storage System under Wind Uncertainties in a Microgrid. IEEE Trans. Power Syst. 2018, 33, 2292-2300. [CrossRef]

14. Zhang, Z.; Chow, M.Y. Convergence Analysis of the Incremental Cost Consensus Algorithm Under Different Communication Network Topologies in a Smart Grid. IEEE Trans. Power Syst. 2012, 27, 1761-1768. [CrossRef]

15. Xu, Y.; Zhang, W.; Hug, G.; Kar, S.; Li, Z. Cooperative Control of Distributed Energy Storage Systems in a Microgrid. IEEE Trans. Smart Grid 2015, 6, 238-248. [CrossRef]

16. Xu, Y.; Li, Z. Distributed Optimal Resource Management Based on the Consensus Algorithm in a Microgrid. IEEE Trans. Ind. Electron. 2015, 62, 2584-2592. [CrossRef] 
17. Zhao, T.; Zuo, Z.; Ding, Z. Cooperative control of distributed battery energy storage systems in Microgrids. In Proceeding of the 35th Chinese Control Conference, Chengdu, China, 27-29 July 2016; pp. 10019-10024. [CrossRef]

18. Zhao, T.; Ding, Z. Distributed Agent Consensus-Based Optimal Resource Management for Microgrids. IEEE Trans. Sustain. Energy 2018, 9, 443-452. [CrossRef]

19. Wang, Z.; Wu, W.; Zhang, B. A Fully Distributed Power Dispatch Method for Fast Frequency Recovery and Minimal Generation Cost in Autonomous Microgrids. IEEE Trans. Smart Grid 2016, 7, 19-31. [CrossRef]

20. Khatibzadeh, A.; Besmi, M.; Mahabadi, A.; Haghifam, M.R. Multi-Agent-Based Controller for Voltage Enhancement in AC/DC Hybrid Microgrid Using Energy Storages. Energies 2017, 10. [CrossRef]

21. Qi, X.; Bai, Y. Improved Linear Active Disturbance Rejection Control for Microgrid Frequency Regulation. Energies 2017, 10, 1047. [CrossRef]

22. Olfati-Saber, R.; Fax, J.A.; Murray, R.M. Consensus and Cooperation in Networked Multi-Agent Systems. Proc. IEEE 2007, 95, 215-233. [CrossRef]

23. Wood, A.J.; Wollenberg, B.F. Power Generation, Operation, Control; John Wiley \& Sons: Hoboken, NJ, USA, 1996; pp. 32-33.

(C) 2018 by the authors. Licensee MDPI, Basel, Switzerland. This article is an open access article distributed under the terms and conditions of the Creative Commons Attribution (CC BY) license (http:/ / creativecommons.org/licenses/by/4.0/). 